\title{
Correction to: 3D Printing in Fiber-Device Technology
}

\author{
Louis van der Elst ${ }^{1,2}$. Camila Faccini de Lima ${ }^{1,2} \cdot$ Merve Gokce Kurtoglu ${ }^{1,2} \cdot$ Veda Narayana Koraganji ${ }^{1,2}$. \\ Mengxin Zheng ${ }^{1,2} \cdot$ Alexander Gumennik ${ }^{1,2}$
}

Published online: 16 April 2021

(C) The Author(s) 2021

\section{Correction to: Advanced Fiber Materials \\ https://doi.org/10.1007/s42765-020-00056-6}

Due to an unfortunate mistake the name of an author has been misspelled. It should read: Merve Gokce Kurtoglu.

Further, the statement on author contributions should be edited to: "Camila Faccini de Lima, Louis van der Elst, Merve Gokce Kurtoglu, Mengxin Zheng and Veda Narayana Koraganji equally contributed to this work."

The original article can be found online at https://doi.org/10.1007/ s42765-020-00056-6.

\section{Alexander Gumennik}

gumennik@iu.edu

1 Department of Intelligent Systems Engineering, Luddy School of Informatics, Computing and Engineering, Indiana

University Bloomington, 700 North Woodlawn Avenue,

Bloomington, IN 47408, USA

2 Fibers and Additive Manufacturing Enabled Systems

Laboratory, 2425 North Milo B Sampson Lane,

Bloomington, IN 47408, USA 